\title{
Umami: The Taste That Drives Purine Intake
}

Rheumatologists commonly recommend low purine diets to gouty subjects based on studies linking the purine contents of food to increased risk for gout ${ }^{1}$. However, most rheumatologists, as well as physicians in general, do not know that one of the basic 5 human tastes is for purine-rich foods, a taste known as umami (oo-mah-mee). We present evidence of this revelation and why this may have occurred.

Historically, an elevation in serum urate was considered benign except for carrying an increased risk for gout. Recently, soluble urate has been found to have myriad biologic effects, including raising blood pressure, increasing hepatic fat stores, and inducing insulin resistance ${ }^{2,3}$. Indeed, the uricase mutation that occurred in the mid-Miocene likely provided a survival advantage to our ancestors during a period of famine that occurred during that time in Europe ${ }^{4}$.

If uric acid has an important role in human survival, then it is logical that there should be a taste receptor that would encourage the ingestion of foods that raise serum urate. In addition to the classic tastes of sour, bitter, sweet, and salt, there is a fifth basic taste, umami. Umami is the "savory" flavor and was first identified in traditional Japanese foods such as kombu (sea kelp), where it was found to result from the presence of free glutamate. The umami receptor in the taste buds is complex, and consists of the metabotropic glutamate receptor-4, the G-protein-coupled heterodimer of taste receptor type 1 member 1 (TAS1R1), and taste receptor type 1 receptor $3^{5}$. The umami taste is enhanced by the release of glutamate from proteins during ripening, aging, drying, curing, or cooking of foods. However, the umami taste is also amplified (up to 8-fold) by nucleotides such as inosine monophosphate (IMP), guanosine monophosphate (GMP), and adenosine monophosphate (AMP). AMP is relatively higher in seafood and shellfish, IMP in organ meats and animal protein, and GMP in purine-rich vegetables $^{6}$. The molecular mechanism for this synergy was shown to be due to the ability of 5 ' ribonucleotides to enhance the binding of glutamate to the TAS1R1 by binding to an adjacent site, allowing stabilization of the conformational change induced by the binding of glutamate ${ }^{7}$.

Purine-rich foods raise uric acid and are associated with gout in humans ${ }^{1}$. RNA-rich foods such as yeast raise serum urate $^{8}$. RNA is degraded by pancreatic RNases to nucleotides such as IMP, GMP, and AMP, which are further degraded to nucleosides by small-intestine brush-border phosphatases, and then are taken up in enterocytes, where they are degraded stepwise to generate uric acid, which then enters the circulation. In many foods the RNA has already been broken down to IMP, GMP, and AMP, and these are key components of the umami taste. Oral administration of IMP or AMP $(0.1 \mathrm{mmol} / \mathrm{kg}$ body weight $)$, for example, increases serum urate in humans and the increase is greater than that observed with xanthine or guanine ${ }^{9}$.

A major source of umami is beer. While all alcohol raises uric acid, beer contains brewer's yeast, and carries a purine content varying from 120 to $300 \mathrm{mg}$ per serving $(350 \mathrm{ml})$, with slightly lower levels in nonalcoholic beer ${ }^{10}$. Local beers and high malt beers have a purine content that is 100 -fold higher than that present in a serving $(40 \mathrm{ml})$ of whisky ${ }^{10}$. Beer intake carries a higher risk for development of gout than that for other alcohol-containing drinks ${ }^{11}$.

The uric acid response to purine nucleotides varies among individuals. The serum uric acid response to AMP or IMP is greater in subjects with hyperuricemia or gout compared to normouricemic subjects ${ }^{9}$. Similarly, subjects who regularly drink beer show a greater serum uric acid response than subjects who do not regularly drink beer ${ }^{12}$.

Glutamate is a nonessential amino acid that can also stimulate the synthesis of nucleotides and uric acid, likely because of conversion to glutamine in the intestine and liver, where it acts as a nitrogen donor during uric acid synthesis. The administration of glutamate $(0.45 \mathrm{mmol} / 100 \mathrm{~g}$ body weight intraperitoneally) to rats stimulates intrahepatic nucleotide synthesis within hours ${ }^{13}$.

All high-purine foods are umami foods, and the overlap between the groups is significant (Table 1). Because nucleotides contain minimal energy content, the evolutionary reason umami is an attractive taste may relate to the desire to raise nucleotide contents and serum uric acid levels. Recently, we identified a role for uric acid in stimulating hepatic fat accumulation by both stimulating lipo-genesis and blocking fatty acid oxidation ${ }^{3}$. Uric acid also has effects on the vasculature and adipocytes that contribute to a rise in blood pressure and the induction of insulin resistance in animals ${ }^{2}$. Indeed, serum uric acid increased in our ancestors during the Miocene as a consequence of the uricase mutation, where it may have functioned as a survival benefit during the famine that resulted from the global cooling of that period ${ }^{4}$.

While uric acid may have had a beneficial survival effect during starvation, in modern societies an elevated serum urate predicts the development of hypertension, insulin resistance, and fatty liver. While intake of sugars containing fructose raise uric acid and may have a contributory role in causing metabolic syndrome in the United States, we

Personal non-commercial use only. The Journal of Rheumatology Copyright (c) 2013. All rights reserved. 
Table 1. The similarities of high purine and high umami foods.

\begin{tabular}{lc}
\hline High Purine Foods & High Umami Foods \\
\hline Meats & Meats \\
High: organ meats, beef extract & High: organ meats, beef extract \\
Medium: lamb, beef, pork, duck, turkey & Medium: lamb, beef, pork, duck, turkey \\
Seafood & Seafood \\
High: shellfish, shrimp, crab, lobster, squid, & High: shellfish, shrimp, crab, lobster, squid, \\
anchovies, sardines, mackerel, tuna, salmon & anchovies, sardines, mackerel, tuna, salmon \\
Medium: most fish & Medium: most fish \\
Vegetables & Vegetables \\
Medium: soybeans, peas, Brussels sprouts, & Medium: soybeans, peas, tomatoes, red bell peppers, \\
broccoli, spinach & spinach \\
Mushrooms & Mushrooms \\
Medium: portobello, porcini, chanterelle & High: shiitake, portobello, porcini, chanterelle \\
Dairy/cheese & Dairy/cheese \\
Medium: blue cheese, Roquefort & High: parmesan, blue cheese, Roquefort \\
Beverage: beer & Beverage: beer \\
\hline
\end{tabular}

propose that the intake of umami foods may be especially important in raising uric acid in the Asian population. Intake of free glutamate ranges from 550 to $580 \mathrm{mg}$ daily in the UK and 1.2 to $1.7 \mathrm{~g} /$ day in Japan, but some individuals ingest up to $10 \mathrm{~g}$ per day ${ }^{14}$. Japanese individuals appear to have higher intake of glutamate compared to subjects from the $\mathrm{UK}^{14}$, and also have higher serum uric acid levels than those observed in the American population ${ }^{15,16}$. Monosodium glutamate (MSG) induces obesity in mice if given early in life $^{17}$. MSG-treated animals also develop insulin resistance, hypertriglyceridemia, and an increase in abdominal girth ${ }^{18}$. The Chinese Health and Nutrition Survey followed 10,095 healthy Chinese adults for an average of 5.5 years and found high intake of MSG was associated with a higher risk for developing obesity (increased body mass index) ${ }^{14}$. Beer, which is rich in umami-containing nucleotides, is also associated with truncal obesity, elevated blood pressure, and hypertriglyceridemia. Interestingly, a favorite new drink in several countries is red beer, a combination of glutamate-rich tomato juice with purine-rich beer.

Today the restriction of purine-rich foods is primarily the recommendation of rheumatologists who wish to help individuals with gout, and it is important for rheumatologists to know that this is essentially targeting umami-rich foods. Because umami is one of the basic tastes, it emphasizes the difficulty of succeeding with this type of diet. Recently, sugar, and fructose in particular, has also been associated with increased risk for gout ${ }^{19}$ and also for the development of metabolic syndrome ${ }^{20}$. Not surprisingly, the taste for sugar is also one of the 5 basic human tastes, sweet, and there is increasing evidence that fructose was also critical for stimulating fat stores in the past during episodes of human famine ${ }^{4}$. Thus, the desire to raise serum uric acid is deeply seated in our biology and may function to encourage ingestion of foods to raise serum urate. Further studies on the role of umami foods in the metabolic syndrome are warranted.

\author{
RICHARD J. JOHNSON, MD; \\ TAKAHIKO NAKAGAWA, MD, \\ Division of Kidney Diseases and Hypertension, \\ University of Colorado Denver, \\ L. GABRIELA SÁNCHEZ-LOZADA, PhD, \\ Division of Kidney Diseases and Hypertension, \\ University of Colorado Denver; \\ Department of Nephrology, \\ Instituto Nacional de Cardiologia I. Ch., \\ Mexico City, Mexico; \\ MIGUEL A. LANASPA, $\mathrm{PhD}$; \\ YOSHIFURU TAMURA, MD; \\ KATSUYUKI TANABE, $\mathrm{MD}$; \\ TAKUJI ISHIMOTO, MD; \\ JEFFREY THOMAS, MD; \\ SHINICHIRO INABA, MD; \\ WATARU KITAGAWA, MD; \\ CHRISTOPHER J. RIVARD, $\mathrm{PhD}$, \\ Division of Kidney Diseases and Hypertension, \\ University of Colorado Denver, \\ Aurora, Colorado, USA
}

Address correspondence to Dr. R.J. Johnson, Division of Kidney Diseases and Hypertension, University of Colorado Denver, Aurora, Colorado 80045, USA. E-mail: richard.johnson@ucdenver.edu

Dr. Johnson and Dr. Nakagawa have patents and patent applications related to lowering uric acid as a means for treating hypertension, metabolic syndrome, and diabetic kidney disease; and are shareholders in Revascor.

\section{REFERENCES}

1. Choi HK, Atkinson K, Karlson EW, Willett W, Curhan G. Purine-rich foods, dairy and protein intake, and the risk of gout in men. N Engl J Med 2004;350:1093-103.

2. Baldwin W, McRae S, Marek G, Wymer D, Pannu V, Baylis C, et al. Hyperuricemia as a mediator of the proinflammatory endocrine imbalance in the adipose tissue in a murine model of the metabolic syndrome. Diabetes 2011;60:1258-69.

3. Lanaspa MA, Sanchez-Lozada LG, Choi YJ, Cicerchi C, Kanbay M, Roncal-Jimenez CA, et al. Uric acid induces hepatic steatosis by generation of mitochondrial oxidative stress: Potential role in 
fructose-dependent and -independent fatty liver. J Biol Chem 2012;287:40732-44.

4. Johnson RJ, Andrews P. Fructose, uricase, and the back-to-Africa hypothesis. Evol Anthropol 2010;19:250-7.

5. Shigemura N, Shirosaki S, Sanematsu K, Yoshida R, Ninomiya Y. Genetic and molecular basis of individual differences in human umami taste perception. PLoS One 2009;4:e6717.

6. Ninomiya K. Natural occurrence. Food Rev Int 1998;14:177-211.

7. Zhang F, Klebansky B, Fine RM, Xu H, Pronin A, Liu H, et al. Molecular mechanism for the umami taste synergism. Proc Natl Acad Sci USA 2008;105:20930-4.

8. Edozien JC, Udo UU, Young VR, Scrimshaw NS. Effects of high levels of yeast feeding on uric acid metabolism of young man. Nature 1970;228:180.

9. Clifford AJ, Riumallo JA, Youn VR, Scrimshaw NS. Effect of oral purines on serum and urinary uric acid of normal, hyperuricemic and gouty humans. J Nutr 1976;106:428-50.

10. Kaneko K, Yamanobe T, Fujimori S. Determination of purine contents of alcoholic beverages using high performance liquid chromatography. Biomed Chromatogr 2009;23:858-64.

11. Choi HK, Curhan G. Beer, liquor, and wine consumption and serum uric acid level: The Third National Health and Nutrition Examination Survey. Arthritis Rheum 2004;51:1023-9.

12. Ka T, Moriwaki Y, Takahashi S, Yamamoto A, Tsutsumi Z, Inokuchi T, et al. Effects of long-term beer ingestion on plasma concentrations and urinary excretion of purine bases. Horm Metab Res 2005;37:641-5.
13. Feigelson M, Feigelson P. Relationships between hepatic enzyme induction, glutamate formation, and purine nucleotide biosynthesis in glucocorticoid action. J Biol Chem 1966;241:5819-26.

14. He K, Du S, Xun P, Sharma S, Wang H, Zhai F, et al. Consumption of monosodium glutamate in relation to incidence of overweight in Chinese adults: China Health and Nutrition Survey (CHNS). Am J Clin Nutr 2011;93:1328-36.

15. Iseki $\mathrm{K}$, Oshiro $\mathrm{S}$, Tozawa $\mathrm{M}$, Iseki $\mathrm{C}$, Ikemiya $\mathrm{Y}$, Takishita $\mathrm{S}$. Significance of hyperuricemia on the early detection of renal failure in a cohort of screened subjects. Hypertens Res 2001;24:691-7.

16. Fang J, Alderman MH. Serum uric acid and cardiovascular mortality. The NHANES I Epidemiologic Follow-up Study, 1971-1992. National Health and Nutrition Examination Survey. JAMA 2000;283:2404-10.

17. Bunyan J, Murrell EA, Shah PP. The induction of obesity in rodents by means of monosodium glutamate. Br J Nutr 1976;35:25-39.

18. Collison KS, Maqbool ZM, Inglis AL, Makhoul NJ, Saleh SM, Bakheet RH, et al. Effect of dietary monosodium glutamate on HFCS-induced hepatic steatosis: expression profiles in the liver and visceral fat. Obesity 2010;18:1122-34.

19. Choi HK, Curhan G. Soft drinks, fructose consumption, and the risk of gout in men: prospective cohort study. BMJ 2008;336:309-12.

20. Malik VS, Popkin BM, Bray GA, Despres JP, Willett WC, Hu FB. Sugar-sweetened beverages and risk of metabolic syndrome and type 2 diabetes: a meta-analysis. Diabetes Care 2010;33:2477-83.

J Rheumatol 2013;40:1794-6; doi:10.3899/jrheum.130531 